\title{
Hybrid coronary revascularization versus coronary artery bypass grafting for multivessel coronary artery disease: systematic review and meta-analysis
}

Peng Zhu ${ }^{1,2,3}$, Pengyu Zhou ${ }^{1,2}$, Yong Sun ${ }^{1,2,3}$, Yilong Guo ${ }^{2}$, Mingjie Mai ${ }^{2}$ and Shaoyi Zheng ${ }^{2^{*}}$

\begin{abstract}
Background: The concept of hybrid coronary revascularization (HCR) combines the left internal mammary artery (LIMA)-left anterior descending (LAD) graft and percutaneous coronary intervention (PCI) to non-LAD vessels. Multiple comparative studies have evaluated the safety and feasibility of HCR and coronary artery bypass grafting (CABG) for multivessel coronary artery disease (MCAD). However, the sample size of each study was small, and evidences based on single-institutional experience. The purpose of this meta-analysis was to compare the short-term outcomes of HCR with those of CABG for MCAD.
\end{abstract}

Method: PubMed, EMBASE and Cochrane Library databases, as well as conference proceedings, were searched for eligible studies published up to March 2014. We calculated summary odds ratios (OR) for primary endpoints (death, stroke; myocardial infarction (MI); target vessel revascularization (TVR); major adverse cardiac or cerebrovascular events (MACCES)) and secondary endpoints (atrial fibrillation (AF); renal failure; length of stay in the intensive care unit (LoS in ICU); length of stay in hospital (LoS in hospital); red blood cell (RBC) transfusion). Data from 6176 participants were derived from ten cohort studies.

Results: HCR was non-inferior to CABG in terms of MACCEs during hospitalization (odds ratio (OR), 0.68, 95\% confidence interval $(\mathrm{Cl}), 0.34-1.33)$ and at one-year follow-up $(0.32,0.05-1.89)$, and no significant difference was found between HCR and CABG groups in in-hospital and one-year follow-up outcomes of death, MI, stroke, the prevalence of $A F$ and renal failure, whereas HCR was associated with a lower requirement of RBC transfusion and shorter LoS in ICU and LoS in hospital than CABG (weighted mean difference (WMD) $-1.25,95 \% \mathrm{Cl},-1.62$ to $-0.88 ;-17.47,-31.01$ to $-3.93 ;-1.77,-3.07$ to -0.46 ; respectively).

Conclusion: Our meta-analysis indicates that HCR is feasible, safe and effective for the treatment of MCAD, with similar in-hospital and one-year follow-up outcome, significantly lower requirement of RBC transfusion, and faster recovery compared with $C A B G$.

Keywords: Hybrid coronary revascularization, Coronary artery bypass grafting, Multivessel coronary artery disease, Meta-analysis

\footnotetext{
* Correspondence: shaoyizheng@yahoo.com

${ }^{2}$ Department of Cardiovascular Surgery, Guangdong General Hospital,

Guangdong Academy of Medical Sciences, Guangzhou, People's Republic of

China

Full list of author information is available at the end of the article
} 


\section{Introduction}

The revascularization strategy for multivessel coronary artery disease (MCAD) is associated with advantages and disadvantages. Coronary artery bypass grafting (CABG; on-pump and off-pump) offers superior longterm advantages owing largely to the left internal mammary artery (LIMA) to the left anterior descending (LAD) artery graft [1,2]. Conversely, CABG is a relatively aggressive surgical procedure with a higher risk of postoperative stroke [1,3-5], and conduits via the saphenous vein graft have comparatively short-term patency [6,7]. In contrast, percutaneous coronary intervention, a much less invasive method, carries a minimal procedural risk as well as a lower prevalence of failure for the target vessel due to the use of drug-eluting stents (DES) [8,9]. However, those benefits come at the expense of the need for repeat revascularization [2].

The concept of hybrid coronary revascularization (HCR), which combines the LIMA-LAD graft and percutaneous coronary intervention (PCI) to non-LAD vessels, was first introduced by Angelini and colleagues in 1996 [10]. Introduction of HCR has led to concerns as to whether HCR is superior to CABG for MCAD. Multiple comparative studies have evaluated the safety and feasibility of HCR and CABG for MCAD. However, the sample size of each study was small, and evidences based on single-institutional experience [11-21]. The purpose of this meta-analysis was to compare the short-term outcomes of HCR with those of CABG for MCAD.

\section{Review}

\section{Materials and methods}

\section{Study selection and search strategy}

Two independent reviewers (P.Z, and P.Y.Z) searched PubMed, Embase, Web of Science, and the Cochrane Library for randomized controlled trials (RCTs) and nonRCTs up to 1 March 2014 and compared HCR with CABG for MCAD without language or publication restrictions. The following medical subject heading terms and their variants were used in database searches: hybrid coronary revascularization; coronary artery bypass grafting (on-pump or off-pump); multivessel coronary artery disease. Reference lists within selected studies and abstracts published at major international conferences were also searched.

\section{Outcome measures}

The safety endpoints of this meta-analysis were death, stroke, myocardial infarction (MI) and major adverse cardiac or cerebrovascular events (MACCEs). The efficacy endpoint was revascularization. All the primary endpoints were measured in hospital and one year of follow-up. Death was defined as death from any cause.
MI was diagnosed by symptoms, electrocardiography and changes in serum levels of cardiac biomarkers. Target vessel revascularization (TVR) was the need for repeated CABG or percutaneous coronary intervention (PCI). MACCEs were defined as a composite of death, MI, stroke or revascularization.

Secondary outcomes were atrial fibrillation (AF), renal failure (defined as an increase in serum creatinine values $>25 \%$ above baseline values), length of stay in the intensive care unit ( $\mathrm{LoS}$ in ICU), length of stay in hospital (LoS in hospital), and transfusion of red blood cells (RBCs).

\section{Criteria for eligibility of inclusion of studies}

Five main criteria were used: (i) comparison of HCR with CABG for MCAD; (ii) studies reporting at least one of the outcomes mentioned above; (iii) studies documenting surgical procedures such as one-stop HCR or staged HCR,

Table 1 Newcastle-Ottawa scale used for methodological quality assessment of non-RCT

Check list
Selection

Comparability

4、 Group comparable for 1, 2, 3, 4,5 (if yes, 2 stars; one star was assigned if one of these five characteristics was not reported even if there were no other differences between the two groups and other characteristics had been controlled for; 0 star was assigned if the two groups differed)

5、 Group comparable for 6, 7, 8,9,10 (if yes, 2 stars; one star was assigned if one of these four characteristics was not reported even if there were no other differences between the two groups and other characteristics had been controlled for; 0 star was assigned if the two groups differed)

Outcome

assessment

6、 Clearly defined outcome of interest (yes, 1 star for information ascertained by record lincage or interview; 0 star if this information was not reported)

7、 Adequacy of follow-up (1 star if follow-up above 90\%)

Comparability variables: 1 = age; 2 = gender; 3 = diabetes; 4 = hypertension; $5=$ hypercholesterolemia; $6=$ history of cerebrovascular disease; $7=$ previous $\mathrm{PCl} ; 8$ = previous $\mathrm{Ml} ; 9=$ smoking; $10=\mathrm{PVD}$. 


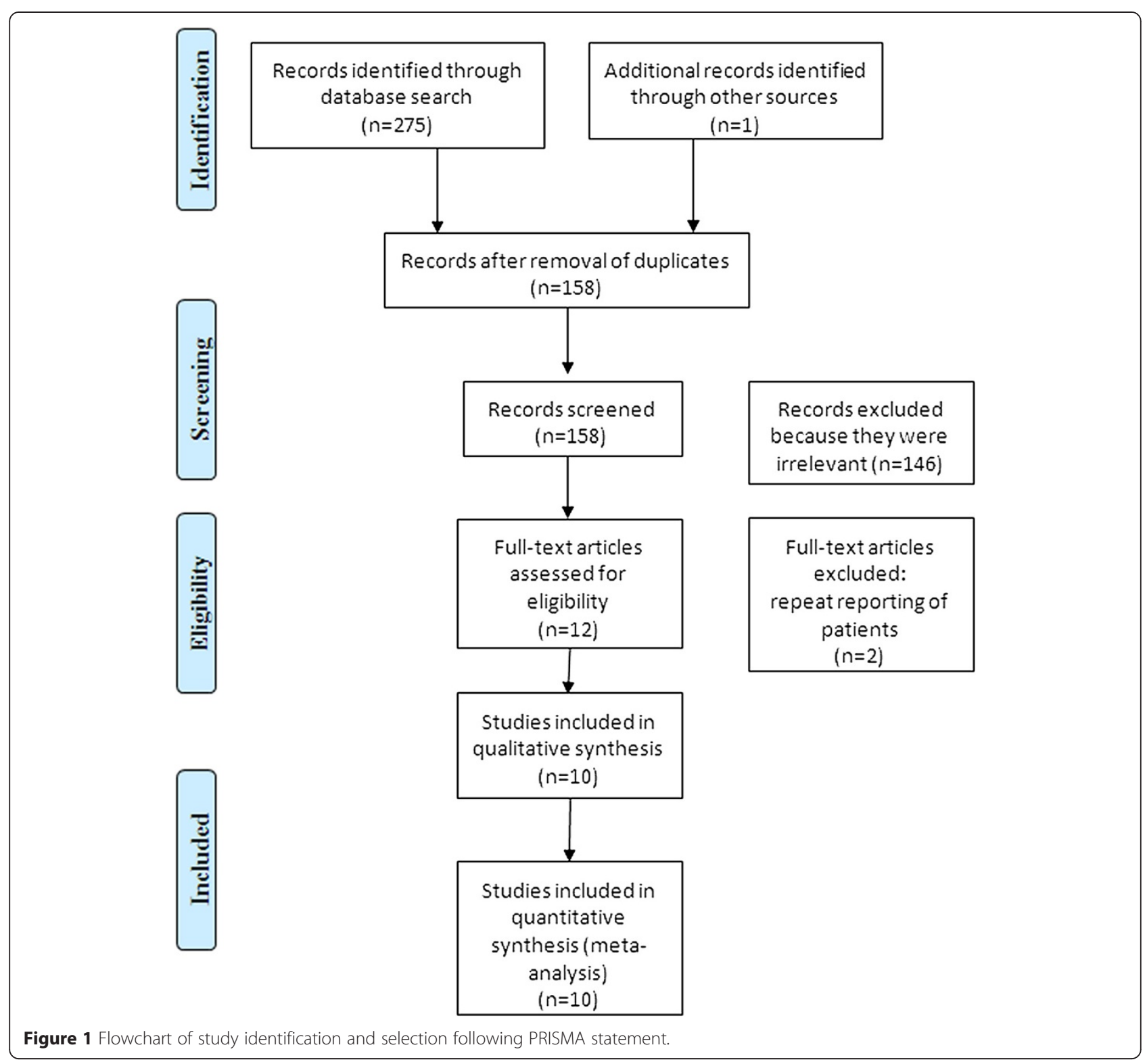

on-pump or off-pump CABG, and documenting surgical methods such as HCR or CABG; (iv) follow-up duration $\geq 30$ days; (v) non-RCTs with a score $>5$ as assessed by the Newcastle-Ottawa Scale (NOS) [22-24].

Assessment of the methodological quality of included studies Three independent authors (Y.S., M.M.J, and Y.L.G) assessed the methodological quality of the included studies, and disagreement was resolved by consensus and discussion. Quality of non-RCTs was evaluated with the modified NOS (http://www.ohri.ca/programs/clinical_ epidemiology/oxford.asp), which addressed three items: patient selection, comparability of groups, and outcome assessment (Table 1).

\section{Statistical analyses}

We undertook statistical analyses using Revman v5.2 (Cochrane Collaboration, Oxford, UK). Continuous and dichotomous variables were assessed by weighted mean differences (WMDs) and odds ratios (OR), respectively. A 95\% confidence interval (CI) was recorded. Heterogeneity among studies was quantified using the I2 statistic. According to Higgins' method, $\mathrm{I}^{2}<25 \%, 25-50 \%$, and $>50$ $\%$ were defined as low, moderate, and high heterogeneity, respectively [25]. A fixed-effect model was applied when $\mathrm{I}^{2}$ $<50 \%$, and a random-effect model employed if $\mathrm{I}^{2}$ was $>50 \% . P<0.05$ was considered significant. Sensitivity analyses were done on primary outcomes by changing the effects model and adjusting inclusion criteria. Publication bias was analyzed by funnel plots and evaluated by Egger's test. 


\section{Results}

We identified ten studies eligible for inclusion: nine non-randomized and one randomized (Figure 1 and Table 2), All of the non-RCTs had a NOS score $>5$ $[11,12,14,16-21]$, which was considered to denote a highquality trial (Table 3). Figure 1 details the process of the identification and selection of studies following the PRISMA statement [26]. Baseline characteristics of patients in the Studies included is shown in Table 4. All studies combined represent outcome data on 6176 patients who underwent $\operatorname{HCR}(n=623)$ or $C A B G$ surgery $(\mathrm{n}=5553)$ from 2007 until present.

\section{Early outcomes (in hospital) Primary clinical outcomes}

Death Five studies reported on in-hospital mortality in 5770 patients. Pooled results showed no significant difference in mortality between the HCR group and CABG group <1 month (OR: 1.21; 95\% CI: 0.55-2.62; $P=0.64$; Figure $2 \mathrm{~A}$ ).

MI Patients treated with HCR did not display a significant reduction in risk for $\mathrm{MI}$ as compared with those who received CABG within hospital (OR: 0.69; 95\% CI: $0.21-2.24 ; P=0.54$; Figure $2 \mathrm{~B})$. Heterogeneity was not observed in this analysis $\left(I^{2}=3 \%\right)$.

Stroke Stroke was assessed in five studies reporting on 5793 patients. The prevalence of stroke was not significantly different between groups. (OR: 1.12; 95\% CI:
0.44-2.86; $P=0.81$; Figure $2 \mathrm{C})$. Heterogeneity was not observed in this analysis $\left(I^{2}=0 \%\right)$.

TVR We analyzed the prevalence of TVR described in the five articles. For four studies, no event occurred in both groups, so we could not undertake a meta-analysis on the prevalence of TVR. In summary, there was insufficient evidence to show that the prevalence of TVR was different between HCR group and CABG group.

MACCEs MACCEs occurred in 2.5\% (10/408) of patients after HCR and 3.6\% (181/5092) of patients with CABG.Six studies (5500 patients) provided data on the prevalence of MACCEs. Pooling of the outcomes of these studies revealed no significant differences in the prevalence of MACCEs between patients treated by HCR and those treated by CABG (OR: $0.68 ; 95 \%$ CI: $0.34-1.33 ; P=0.26$; Figure $2 \mathrm{E})$. Slight heterogeneity was detected in this analysis $\left(I^{2}=2 \%\right)$.

\section{Secondary clinical outcomes}

Five studies reported on AF. [11,16,18,19,21] Four studies reported renal failure $[11,16,17,19,20]$. Six studies reported LoS in ICU $[14,15,17-19,21]$. Five studies reported LoS in hospital $[14,17-19,21]$. Three studies reported transfusion of RBCs [14,17,21].

There was no significant difference in the prevalence of AF between the two groups (OR: 0.93; 95\% CI: $0.70-$ 1.23, $P=0.60)$ or the prevalence of renal failure (OR: 0.73; 95\% CI: $0.36-1.49 ; P=0.39$ ).

Table 2 Main characteristics of included studies

\begin{tabular}{|c|c|c|c|c|c|c|}
\hline Study & Year & $\begin{array}{l}\text { Numbers of patients } \\
\text { (HCR/CABG) }\end{array}$ & Study design & CABG & HCR strategy & $\begin{array}{l}\text { Follow-up } \\
\text { (months) }\end{array}$ \\
\hline Kon [17] & 2007 & $15 / 30$ & Non-RCT & OPCABG & Simultaneous & 12 \\
\hline Zhao [11] & 2008 & $112 / 254$ & Non-RCT & On-pump & Simultaneous & NR \\
\hline Reicher [14] & 2007 & $13 / 26$ & Non-RCT & OPCABG & Simultaneous & 14 \\
\hline \multirow[t]{4}{*}{ Vassiliades [12] } & 2009 & $91 / 4175$ & Non-RCT & OPCABG & $\mathrm{PCl}$ then MICABG & 12 \\
\hline & & & & & $6.6 \%$ & \\
\hline & & & & & MICABG then $\mathrm{PCl}$ & \\
\hline & & & & & $93.4 \%$ & \\
\hline \multirow[t]{2}{*}{ Delhaye [20] } & 2010 & 18/18 & Non-RCT & On-pump & CABG then $\mathrm{PCl}$ & 12 \\
\hline & & & & & OPCABG then $\mathrm{PCl}$ & \\
\hline $\mathrm{Hu}[18]$ & 2010 & 104/104 & Non-RCT & OPCABG & Simultaneous & $18 \pm 7.9$ \\
\hline Halkos [19] & 2011 & $147 / 588$ & Non-RCT & OPCABG & Mainly staged & 38.4 (median) \\
\hline Bachinsky [21] & 2012 & $25 / 27$ & Non-RCT & OPCABG & Simultaneous & 1 \\
\hline Leacche [16] & 2012 & $80 / 301$ & Non-RCT & OPCABG & NR & 1 \\
\hline Popov [15] & Unpublished & $18 / 30$ & RCT & On-pump & MICABG then $\mathrm{PCl}$ & 1 \\
\hline
\end{tabular}

Unless otherwise indicated, data are expressed as mean \pm standard deviation.

$\mathrm{PCl}$, percutaneous coronary intervention; OPCABG, on-pump coronary artery bypass grafting; MICABG, minimally invasive coronary artery bypass grafting NR: not reported. 
Table 3 Assessment of quality of studies

\begin{tabular}{|c|c|c|c|c|c|c|c|c|c|}
\hline \multirow[b]{2}{*}{ Author } & \multirow[b]{2}{*}{ Year } & \multicolumn{3}{|c|}{ Selection } & \multicolumn{2}{|c|}{ Comparability } & \multicolumn{3}{|c|}{ Outcome assessment } \\
\hline & & 1 & 2 & 3 & 4 & 5 & 6 & 7 & Score \\
\hline Kon & 2007 & * & * & $*$ & $*$ & $* *$ & * & - & $* * * * * * *$ \\
\hline Zhao & 2008 & - & $*$ & $*$ & $* *$ & * & $*$ & - & $* * * * * *$ \\
\hline Reicher & 2007 & * & * & * & $* *$ & $* *$ & * & - & $* * * * * * * *$ \\
\hline Vassiliades & 2009 & * & * & $*$ & $* *$ & * & * & $*$ & $* * * * * * * *$ \\
\hline Delhaye & 2010 & * & $*$ & $*$ & $* *$ & $*$ & $*$ & - & $* * * * * * *$ \\
\hline $\mathrm{Hu}$ & 2010 & * & $*$ & $*$ & $* *$ & $* *$ & $*$ & $*$ & $* * * * * * * *$ \\
\hline Halkos & 2011 & * & $*$ & $*$ & $*$ & * & * & - & $* * * * * *$ \\
\hline Bachinsky & 2012 & - & * & $*$ & $* *$ & $* *$ & $*$ & - & $* * * * * * *$ \\
\hline Leacche & 2012 & - & * & * & $* *$ & * & * & - & $* * * * * *$ \\
\hline
\end{tabular}

-:zero point, *: One point, **: Two points.

HCR was associated with a significantly shorter LoS in ICU (29.99 vs.47.85 h; WMD: $-17.47 \mathrm{~h}$; $95 \% \mathrm{CI}:-31.01$ to $-3.93 ; P=0.01)$, LoS in hospital (5.44 vs. 7.30 days; WMD: -1.77 days; $95 \% \mathrm{CI},-3.07$ to $-0.46 ; P=0.008)$, and fewer instances of RBC transfusion (0.26 vs. 1.55U; WMD: -1.25 U; $95 \%$ CI, -1.62 to $-0.88 ; P<0.001$ ) (Table 5).
Longer-term outcomes (One year of follow-up)

MACCEs occurred in 2.9\% (4/137) of patients after HCR and $11.8 \%(18 / 152)$ of patients with CABG at one year of follow-up. The ORs for MACCEs were not significantly different at one year of follow-up (OR: 0.32; 95\% CI: $0.05-1.89, P=0.21$; Figure $3 \mathrm{E})$. As shown in

Table 4 Baseline characteristics of Patients in the Studies included

\begin{tabular}{|c|c|c|c|c|c|c|c|c|c|}
\hline Author & Group & $\mathbf{N}$ & Age $(y)$ & Male (\%) & Diabetes (\%) & Hypertension (\%) & Previous MI (\%) & $\begin{array}{l}\text { History of } \\
\text { cerebrovascular } \\
\text { disease (\%) }\end{array}$ & Smoking (\%) \\
\hline \multirow[t]{2}{*}{ Kon } & $\mathrm{HCR}$ & 15 & $61 \pm 10$ & 73 & 27 & 87 & 67 & 7 & 27 \\
\hline & CABG & 30 & $65 \pm 10$ & 63 & 40 & 80 & 57 & 0 & 33 \\
\hline \multirow[t]{2}{*}{ Zhao } & $\mathrm{HCR}$ & 112 & $63(32-85)$ & 71 & 39 & 82 & 17 & 8 & 68 \\
\hline & CABG & 254 & 63(32-89) & 76 & 39 & 83 & 12 & 8 & 63 \\
\hline \multirow[t]{2}{*}{ Reicher } & $\mathrm{HCR}$ & 13 & $62 \pm 10$ & 80 & 29 & 87 & 47 & 0 & 36 \\
\hline & CABG & 26 & $64 \pm 10$ & 83 & 41 & 75 & 50 & 0 & 36 \\
\hline \multirow[t]{2}{*}{ Vassiliades } & $\mathrm{HCR}$ & 91 & $65 \pm 14$ & 67 & 41 & 82 & 42 & 17 & 53 \\
\hline & CABG & 4175 & $63 \pm 12$ & 69 & 37 & 83 & 48 & 18 & 69 \\
\hline \multirow[t]{2}{*}{ Delhaye } & $\mathrm{HCR}$ & 18 & $62(55-70)$ & 78 & 45 & 67 & 28 & 11 & 44 \\
\hline & CABG & 18 & $60(53-68)$ & 78 & 39 & 78 & 17 & 0 & 39 \\
\hline \multirow[t]{2}{*}{$\mathrm{Hu}$} & $\mathrm{HCR}$ & 104 & $62 \pm 10$ & 11 & 25 & 60 & 34 & 9 & 56 \\
\hline & CABG & 104 & $62 \pm 8$ & 20 & 27 & 63 & 29 & 6 & 37 \\
\hline \multirow[t]{2}{*}{ Haloks } & $\mathrm{HCR}$ & 147 & $64 \pm 13$ & 62 & 60 & 87 & 17 & 20 & 42 \\
\hline & CABG & 588 & $64 \pm 13$ & 71 & 64 & 85 & 12 & 17 & 50 \\
\hline \multirow[t]{2}{*}{ Bachinsky } & $\mathrm{HCR}$ & 25 & $63 \pm 11$ & 80 & 36 & 72 & 20 & 4 & 28 \\
\hline & CABG & 27 & $67 \pm 11$ & 59 & 48 & 96 & 44 & 15 & 22 \\
\hline \multirow[t]{2}{*}{ Leacche } & $\mathrm{HCR}$ & 80 & 64 & 76 & 40 & 86 & 16 & 6 & NR \\
\hline & CABG & 301 & 63 & 77 & 37 & 83 & 16 & 10 & NR \\
\hline \multirow[t]{2}{*}{ Popov } & $\mathrm{HCR}$ & 18 & $60 \pm 6$ & 86 & 16 & 100 & NR & 14 & NR \\
\hline & CABG & 30 & $59 \pm 4$ & 83 & 17 & 100 & NR & 0 & $N R$ \\
\hline
\end{tabular}

Data between parentheses represent median and 25th and 75th percentiles. Data with \pm symbol represent mean and SD. 


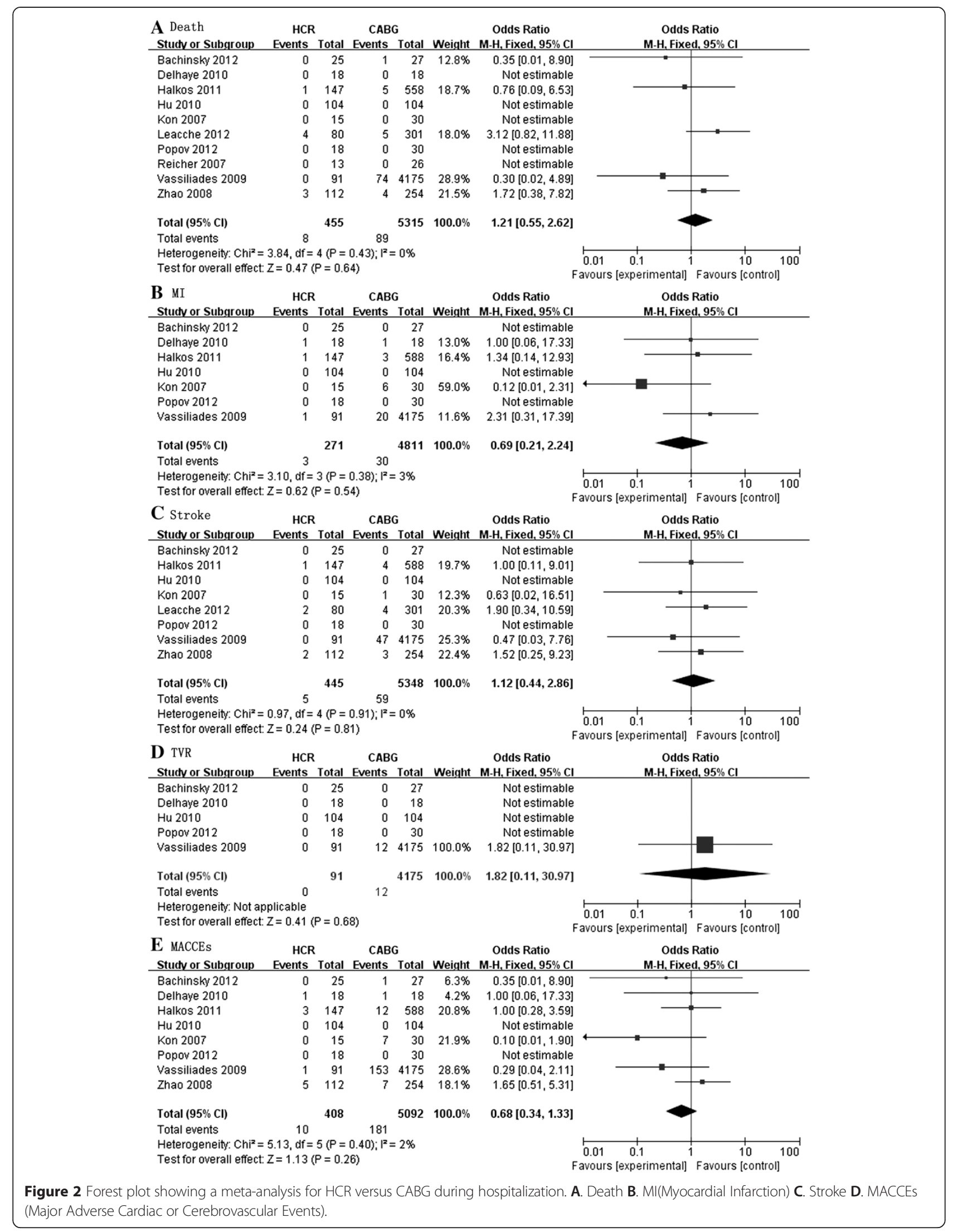


Table 5 Results of meta-analysis of the secondary outcome

\begin{tabular}{lllllllll}
\hline Outcome measures & Number of studies & $\begin{array}{l}\text { Patients } \\
\text { (HCR/CABG) }\end{array}$ & I2 (\%) & Analysis model & Statistics method & OR/WMD & $\mathbf{9 5 \%}$ Cl & p value \\
\hline AF & 5 & $468 / 1274$ & 0 & Fixed & M-H & 0.93 & $0.70,1.23$ & 0.60 \\
Renal Failure & 5 & $372 / 1191$ & 0 & Fixed & M-H & 0.64 & $0.32,1.27$ & 0.20 \\
Intubation Time & 3 & $132 / 160$ & 93 & Random & IV & -9.95 & $-18.58,-1.31$ & 0.02 \\
LOS in ICU & 6 & $322 / 805$ & 85 & Random & IV & -17.47 & $-31.01,-3.93$ & 0.01 \\
LOS in hospital & 5 & $304 / 775$ & 82 & Random & IV & -1.77 & $-3.07,-0.46$ & 0.008 \\
Red Blood Cells Transfusion & 3 & $53 / 83$ & 0 & Fixed & IV & -1.25 & $-1.62,-0.88$ & P $<0.00001$ \\
\hline
\end{tabular}

OR odds ratio, WMD Weighted mean difference, M-H Mantel-Haenszel, IV inverse variance, Cl confidence interval, AF atrial fibrillation, LOS in ICU lengths of stay in Intensive Care Unit, LOS in hospital lengths of stay in hospital.

Figure $3 \mathrm{~A}, 3 \mathrm{~B}, 3 \mathrm{C}$, and $3 \mathrm{D}$, overall, the outcomes for death, MI, Stroke and TVR at one year of follow-up were not statistically different.

\section{Sensitivity analyses and publication bias}

Sensitivity analyses were undertaken on the outcomes mentioned above by re-analyses using a different effects model by including studies with $\geq 80$ patients in each group and including non-RCTs with a score $>6$ as assessed by the NOS.

Analyses of non-RCTs studies with a score $>6$ separately also did not substantively alter the overall result of our analyses. Moreover, changing the model did not substantially change the pooled point estimate.

Inclusion of studies with $\geq 80$ patients in each group did not substantially change the pooled point estimate except for LoS in ICU and LoS in hospital. Pooling the outcomes of these studies revealed no significant difference in the LoS in ICU (WMD: $-10.47 \mathrm{~h}, 95 \% \mathrm{CI}$ : -35.00 to $14.07 ; P=0.40$ ) or LoS in hospital (WMD: -0.42 days; $95 \% \mathrm{CI}:-2.19$ to $1.34 ; P=0.64$ ) between the two groups.

In summary, the results of sensitivity analyses supported the credibility of most of the evidences in this meta-analysis, but the credibility of the evidences about LoS in ICU and LoS in hospital should be considered carefully.

Also, we assessed for publication bias of data by Egger's test and visual assessment of funnel plots. For the endpoint of in-hospital MACCEs, Egger's test revealed $P=0.694$, showing no evidence of publication bias.

\section{Discussion}

In this meta-analysis, HCR was non-inferior to CABG in terms of in-hospital and one-year follow-up outcomes of death, MI, stroke, TVR, MACCEs, and some surgical complications (including $\mathrm{AF}$ and renal failure) whereas HCR was associated with a reduced need for RBC transfusion as well as shorter LoS in ICU and LoS in hospital than CABG.
We revealed no significant differences in the prevalence of in-hospital and one-year follow-up mortality, MI, stroke, TVR, MACCEs between the two groups, findings which were consistent with the early results of an ongoing RCT [15]. In that RCT, there was no mortality, MACCEs, or TVR in the hospital. The adequate design of that study (a prospective, randomized pilot trial to compare HCR with CABG in patients with MCAD) provided the preliminary data to strengthen the evidences of our study.

The prevalence of in-hospital one-year follow-up mortality, MI, stroke and MACCEs were similar between the two groups, however, we hypothesized that HCR may be superior to CABG in terms of long-term MACCEs. Hu et al. [18] reported a lower prevalence of MACCEs after HCR compared with on-pump CABG (1.0\% vs 9.6\%) after a mean follow-up of 18 months. Shen et al. [13] also reported that, after a mean follow-up of 3 years, in the high Euro-SCORE tertile, the prevalence of MACCEs in the hybrid group was significantly lower than that in the CABG group $(P=0.030)$.

As duration of follow-up extends, HCR may be superior to CABG in terms of long-term MACCEs.Several reasons support this findings mentioned above. Firstly, avoiding aortic clamping is one of the unique advantages of the hybrid procedure. Aortic manipulation (a predictor of postoperative cerebral infarction) is necessary during on-pump CABG [27]. Secondly, in the hybrid procedure, the quality of LIMA-LAD grafting is confirmed further by prompt angiography and deficiencies can be corrected immediately and reliably [28-30]. Finally, the less invasive nature of the hybrid procedure plays an important part in patient recovery.

Cardiac surgery and administration of contrast dyes during PCI tends to increase the risk of renal failure. Hence, we suggest that the prevalence of renal dysfunction might be higher in patients treated with HCR compared with those undergoing CABG alone. In this meta-analysis, however, no significant difference in the prevalence of renal failure was found between the two groups. The more stable hemodynamics and better urine 


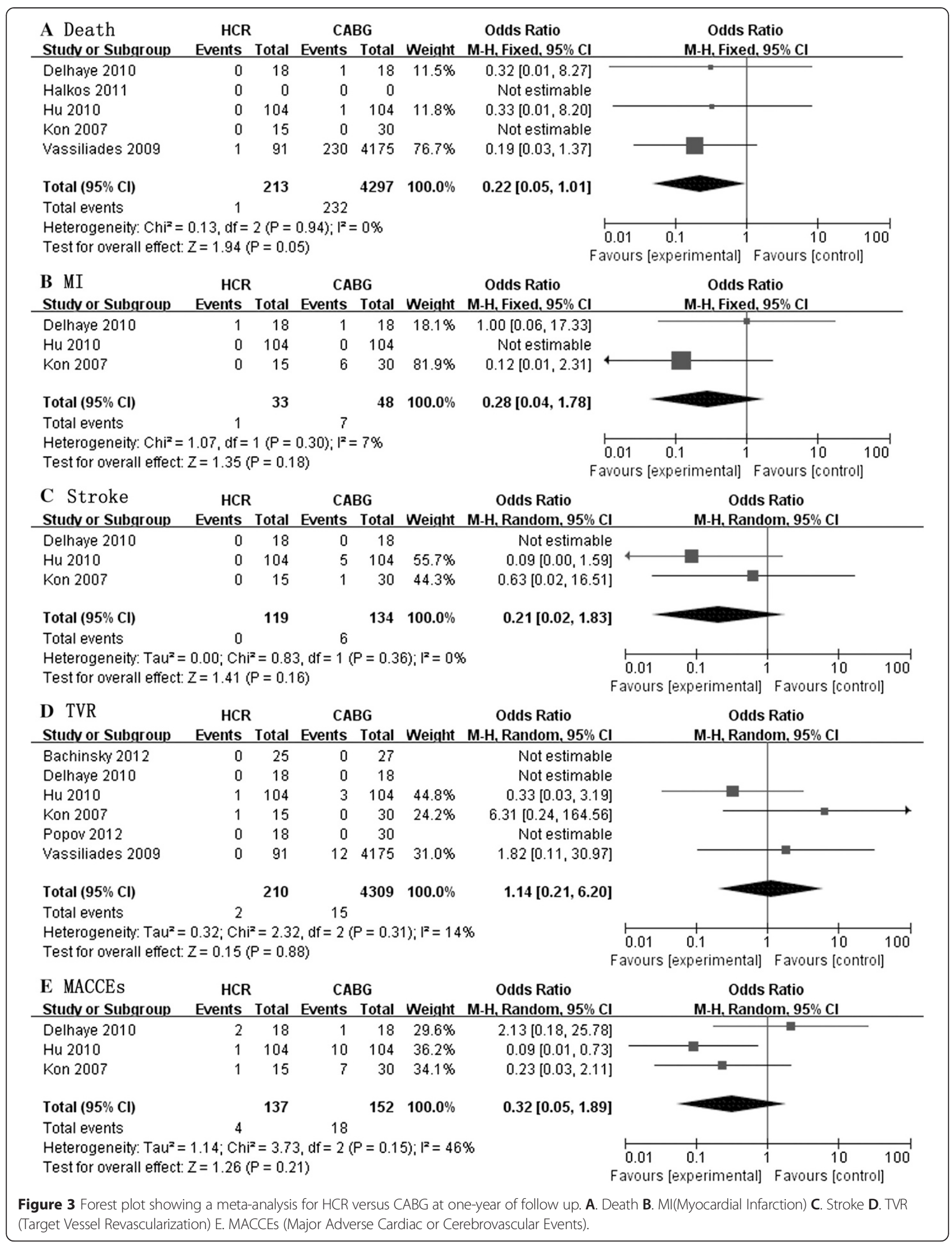


output in the hybrid group may have resulted in a similar prevalence of renal failure in the present study $[31,32]$.

In this analysis, the significantly lower requirement of RBC transfusion in the HCR group was attributed to the less invasive nature of minimally invasive direct coronary artery bypass grafting in the hybrid procedure despite continuous perioperative use of aspirin and perioperative administration of clopidogerl $[12,14,31]$.

LoS in ICU and LoS in hospital were significantly shorter in the HCR group in this analysis, so the hybrid group had a shorter recovery with a substantial reduction in utilization of hospital resources [33]. This phenomenon could be explained in two ways. Firstly, a lower requirement of blood transfusion and reduced systemic inflammation have been associated with improved postoperative morbidity in a series of studies comparing minimally invasive and conventional surgery, and probably play a part in the outcomes of hybrid surgery. Secondly, better myocardial protection (as reflected by a reduction in regional release of myoglobin and systemic release of troponin I) might be another mechanism for quicker recovery after the hybrid procedure [17].

Heterogeneity among studies was observed for several continuous variables, including LoS in ICU and LoS in hospital. This heterogeneity may have resulted from variations in the surgeon's caseload, the learning-curve effect, the HCR procedure, perioperative management, and standards regarding hospital discharge among the included studies.

\section{Limitations}

This meta-analysis had several limitations. The main limitation of our meta-analysis was the retrospective nature of the available data. No RCT has been published but two protocols have been registered (available at http:// www.clinicaltrials.gov/ct2/show/NCT01699048 and http:// www.clinicaltrials.gov/ct2/show/NCT01035567). Ideally, a meta-analysis should include RCTs only, but inclusion of high-quality non-RCTs can improve the statistical power while maintaining an acceptable level of evidence. Abrahama et al. [34] reported that a meta-analysis of welldesigned comparative non-RCTs of surgical procedures was as accurate as a meta-analysis of RCTs. Also, evaluation of publication bias cannot be done in a robust manner with such few data points, so the statistical power of Egger's test to alert suspicion of publication bias was very limited in our meta-analysis. Therefore, more RCTs comparing HCR with CABG in patients with MCAD are necessary.

Secondly, the duration of clinical follow-up was limited to one year in most studies, whereas a meta-analysis of long-term outcomes was not possible due to insufficient data $[12,13,17,18,20]$. Hence, more long-term results will be necessary for future studies.
Thirdly, the definition of endpoints such as MI, MACCEs, and renal failure in different studies varied to some degree, which may have weakened the evidences in our analysis.

Finally, obvious heterogeneity was observed for several continuous variables. Therefore, the random-effects model was used.

\section{Conclusion}

This meta-analysis suggested that HCR is feasible, safe and effective for treatment of MCAD, with similar inhospital and one-year follow-up outcomes, significantly lower requirement for RBC transfusion, and faster recovery compared with CABG. It may provide a safe and effective alternative for treating selected patients with MCAD. However, to validate the long-term results of HCR for MCAD, more large-scale, multicenter, prospective RCTs are warranted.

\section{Abbreviations \\ HCR: Hybrid coronary revascularization; CABG: Coronary artery bypass grafting; MCAD: Multivessel coronary artery disease; OR: Odds ratios; MI: Myocardial infarction; TVR: Target vessel revascularization; MACCEs: Major adverse cardiac or cerebrovascular events; AF: Atrial fibrillation; LoS: Length of stay; ICU: Intensive care unit; RBC: Red bloodcell; Cl: Confidence iinterval; WMD: Weighted mean difference; LIMA: Left internal mammary artery; LAD: Left anterior descending; DES: Drug-eluting stents; PCl: Percutaneous coronary intervention; RCTs: Randomized controlled trials; NOS: Newcastle-ottawa scale.}

\section{Competing interests}

The authors declare that they have no competing interests.

\section{Authors' contributions}

ZPeng and ZPengyu searched internet for RCTs and non-RCTs sutdies about comparison of HCR and CABG for MCAD. SY, MM and GY assessed the methodological quality of the included studies. Zhu Peng and ZPengyu participated in the design of the study and performed the statistical analysis. ZS conceived of the study, and participated in its design and coordination and helped to draft the manuscript. All authors read and approved the final manuscript.

\section{Acknowledgments}

We thank Professor Vadim Popov (Chief of Cardiac Surgery, Kemerovo Center of Cardiology and Cardiac Surgery, Kemerovo Oblast, Russia) for providing additional data pertaining to their ongoing RCT (Available at: http://www.clinicaltrials.gov/ct2/show/NCT01699048).

\section{Author details}

${ }^{1}$ Department of Cardiovascular Surgery, Southern Medical University, Guangzhou, People's Republic of China. '2Department of Cardiovascular Surgery, Guangdong General Hospital, Guangdong Academy of Medical Sciences, Guangzhou, People's Republic of China. ${ }^{3}$ Department of Cardiovascular Surgery, Xiamen Heart Center, Xiamen, People's Republic of China.

Received: 7 October 2014 Accepted: 17 April 2015

Published online: 01 May 2015

\section{References}

1. Guyton RA. Coronary artery bypass is superior to drug-eluting stents in multivessel coronary artery disease. Ann Thorac Surg. 2006;81:1949-57.

2. Serruys PW, Morice MC, Kappetein AP, Colombo A, Holmes DR, Mack MJ, et al. Percutaneous coronary intervention versus coronary-artery bypass grafting for severe coronary artery disease. N Engl J Med. 2009;360:961-72. 
3. Sabik 3rd JF, Lytle BW, Blackstone EH, Houghtaling PL, Cosgrove DM Comparison of saphenous vein and internal thoracic artery graft patency by coronary system. Ann Thorac Surg. 2005;79:544-51. discussion 44-51.

4. Palmerini T, Biondi-Zoccai G, Riva DD, Mariani A, Savini C, Di Eusanio M, et al. Risk of stroke with percutaneous coronary intervention compared with on-pump and off-pump coronary artery bypass graft surgery: Evidence from a comprehensive network meta-analysis. Am Heart J. 2013;165:910-17.e14.

5. Farkouh ME, Domanski M, Sleeper LA, Siami FS, Dangas G, Mack M, et al. Strategies for multivessel revascularization in patients with diabetes. N Engl J Med. 2012;367:2375-84

6. Desai ND, Cohen EA, Naylor CD, Fremes SE. A randomized comparison of radial-artery and saphenous-vein coronary bypass grafts. N Engl J Med. 2004:351:2302-9.

7. Yun $\mathrm{KL}$, Wu Y, Aharonian $\mathrm{V}$, Mansukhani P, Pfeffer TA, Sintek CF, et al. Randomized trial of endoscopic versus open vein harvest for coronary artery bypass grafting: six-month patency rates. J Thorac Cardiovasc Surg. 2005;129:496-503.

8. Salam AM, Al Suwaidi J, Holmes Jr DR. Drug-eluting coronary stents. Curr Probl Cardiol. 2006:31:8-119.

9. Kubler P, Reczuch K. The use of drug-eluting stents in acute myocardial infarction - is the battle coming to an end? From despair to acceptance. Postepy Kardiologii Interwencyjnej= Advances Interventional Cardiol. 2013:9:50-4.

10. Angelini GD, Wilde P, Salerno TA, Bosco G, Calafiore AM. Integrated left small thoracotomy and angioplasty for multivessel coronary artery revascularisation. Lancet. 1996;347:757-8.

11. Zhao DX, Leacche M, Balaguer JM, Boudoulas KD, Damp JA, Greelish JP, et al. Routine intraoperative completion angiography after coronary artery bypass grafting and 1-stop hybrid revascularization results from a fully integrated hybrid catheterization laboratory/operating room. J Am Coll Cardiol. 2009;53:232-41.

12. Vassiliades TA, Kilgo PD, Douglas JS, Babaliaros VC, Block PC, Samady H, et al. Clinical outcomes after hybrid coronary revascularization versus offpump coronary artery bypass: a prospective evaluation. Innov (Philadelphia, Pa). 2009;4:299-306.

13. Shen $L$, Hu S, Wang $H$, Xiong H, Zheng $Z$, Li L, et al. One-stop hybrid coronary revascularization versus coronary artery bypass grafting and percutaneous coronary intervention for the treatment of multivessel coronary artery disease 3-year follow-Up results from a single institution. J Am Coll Cardiol. 2013;61:2525-33.

14. Reicher B, Poston RS, Mehra MR, Joshi A, Odonkor P, Kon Z, et al. Simultaneous "hybrid" percutaneous coronary intervention and minimally invasive surgical bypass grafting: Feasibility, safety, and clinical outcomes. Am Heart J. 2008;155:661-7.

15. Popov V, Kozyrin K, Malyshenko E, Ganyukov V. Hybrid approach to myocardial revascularization: Early results of randomized trial. Innov Technol Tech Cardiothorac Vasc Surg. 2013;8:99.

16. Leacche M, Byrne JG, Solenkova NS, Reagan B, Mohamed TI, Fredi JL, et al. Comparison of 30-day outcomes of coronary artery bypass grafting surgery verus hybrid coronary revascularization stratified by SYNTAX and euroSCORE. J Thorac Cardiovasc Surg. 2013;145:1004-12.

17. Kon ZN, Brown EN, Tran R, Joshi A, Reicher B, Grant MC, et al. Simultaneous hybrid coronary revascularization reduces postoperative morbidity compared with results from conventional off-pump coronary artery bypass. J Thorac Cardiovasc Surg. 2008;135:367-75.

18. Hu S, Li Q, Gao P, Xiong H, Zheng Z, Li L, et al. Simultaneous hybrid revascularization versus Off-pump coronary artery bypass for multivessel coronary artery disease. Ann Thorac Surg. 2011;91:432-8.

19. Halkos ME, Vassiliades TA, Douglas JS, Morris DC, Rab ST, Liberman HA, et al. Hybrid coronary revascularization versus Off-pump coronary artery bypass grafting for the treatment of multivessel coronary artery disease. Ann Thorac Surg. 2011;92:1695-701.

20. Delhaye C, Sudre A, Lemesle G, Vanesson L, Koussa M, Fayad G, et al. Hybrid revascularization, comprising coronary artery bypass graft with exclusive arterial conduits followed by early drug-eluting stent implantation, in multivessel coronary artery disease. Arch Cardiovasc Dis. 2010;103:502-11.

21. Bachinsky WB, Abdelsalam M, Boga G, Kiljanek L, Mumtaz M, McCarty C. Comparative study of same sitting hybrid coronary artery revascularization versus Off-pump coronary artery bypass in multivessel coronary artery disease. J Interv Cardiol. 2012;25:460-8.
22. Stang A. Critical evaluation of the Newcastle-Ottawa scale for the assessment of the quality of nonrandomized studies in meta-analyses. Eur J Epidemiol. 2010;25:603-5.

23. Deeks JJ, Dinnes J, D'Amico R, Sowden AJ, Sakarovitch C, Song F, et al. Evaluating non-randomised intervention studies. Health Technol Assess (Winchester, England). 2003;7:1-173. iii-x.

24. Athanasiou T, Al-Ruzzeh S, Kumar P, Crossman MC, Amrani M, Pepper JR, et al. Off-pump myocardial revascularization is associated with less incidence of stroke in elderly patients. Ann Thorac Surg. 2004;77:745-53.

25. Yang $Y$, Wang F, Zhang P, Shi C, Zou Y, Qin H, et al. Robot-assisted versus conventional laparoscopic surgery for colorectal disease, focusing on rectal cancer: a meta-analysis. Ann Surg Oncol. 2012;19:3727-36.

26. Moher D, Liberati A, Tetzlaff J, Altman DG. Preferred reporting items for systematic reviews and meta-analyses: the PRISMA statement. J Clin Epidemiol. 2009;62:1006-12.

27. Kotoh K, Fukahara K, Doi T, Nagura S, Misaki T. Predictors of early postoperative cerebral infarction after isolated off-pump coronary artery bypass grafting. Ann Thorac Surg. 2007;83:1679-83.

28. Hol PK, Lingaas PS, Lundblad R, Rein KA, Vatne $K$, Smith HJ, et al. Intraoperative angiography leads to graft revision in coronary artery bypass surgery. Ann Thorac Surg. 2004;78:502-5. discussion 05.

29. Barstad RM, Fosse E, Vatne K, Andersen K, Tonnessen TI, Svennevig JL, et al Intraoperative angiography in minimally invasive direct coronary artery bypass grafting. Ann Thorac Surg. 1997;64:1835-9.

30. Bonatti J, Danzmayr M, Schachner T, Friedrich G. Intraoperative angiography for quality control in MIDCAB and OPCAB. Eur J Cardio-Thoracic Surg Off J Eur Assoc Cardio-Thoracic Surgery. 2003;24:647-9.

31. Zhou S, Fang Z, Xiong H, Hu S, Xu B, Chen L, et al. Effect of one-stop hybrid coronary revascularization on postoperative renal function and bleeding: $A$ comparison study with off-pump coronary artery bypass grafting surgery. J Thorac Cardiovasc Surg. 2014;147:1511-6.

32. Weir MR, Aronson S, Avery EG, Pollack Jr CV. Acute kidney injury following cardiac surgery: role of perioperative blood pressure control. Am J Nephrol. 2011;33:438-52.

33. Halkos ME, Walker PF, Vassiliades TA, Douglas JS, Devireddy C, Guyton RA, et al. Clinical and angiographic results after hybrid coronary revascularization. Ann Thorac Surg. 2014;97:484-91.

34. Abraham NS, Byrne CJ, Young JM, Solomon MJ. Meta-analysis of well-designed nonrandomized comparative studies of surgical procedures is as good as randomized controlled trials. J Clin Epidemiol. 2010;63:238-45.

\section{Submit your next manuscript to BioMed Central and take full advantage of:}

- Convenient online submission

- Thorough peer review

- No space constraints or color figure charges

- Immediate publication on acceptance

- Inclusion in PubMed, CAS, Scopus and Google Scholar

- Research which is freely available for redistribution 